\title{
Robótica livre como alternativa didática para a aprendizagem de Música
}

\begin{abstract}
Sabrina F. Antunes - Instituto Federal de Educação, Ciência e Tecnologia do Rio Grande do Sul (IFRS), sabrina.antunes@ rolante.ifrs.edu.br

Adriano C. Teixeira - Programa de Pós-Graduação em Educação - Universidade de

Passo Fundo (UPF), teixeira@upf.br

Mario Pireddu - Dipartimento di Scienze della Formazione, mario.pireddu @ gmail.com

Resumo: Com a publicação da Lei 11.769/2008, que obriga o ensino de Música na educação básica, é urgente criar soluções para minimizar a carência de instrumentos musicais nas escolas e o número insuficiente de professores com formação em Música. Este artigo objetiva apresentar uma pesquisa acerca de um dispositivo eletrônico baseado em robótica livre para apoio ao ensino de Música a partir do método Orff. O trabalho de campo caracterizou-se como exploratório de cunho qualitativo e realizou-se a partir de quatro oficinas com quatro sujeitos com idade entre 10 e 12 anos. Com o estudo, verificou-se que o dispositivo criado teve potente atuação no processo de avaliação da aprendizagem por parte dos alunos e, em última análise, que a robótica caracteriza-se como uma tecnologia potente para a criação de dispositivos para apoio à aprendizagem de música.
\end{abstract}

Palavras-chave: Robótica educativa; Ensino de Música; Método Orff.

Abstract: With the publication of Law 11.769/2008, which obliges the teaching of music in basic education, comes an urgent context to create solutions to minimize the lack of musical instruments in schools and the insufficient number of teachers with specific training in music. The present paper aims to present the research results that created an electronic device based on open robotics to support the teaching of Music by the Orff method. The field research was characterized as qualitative exploratory and was carried out by 4 workshops with four subjects between the ages of ten and twelve. With the study, it was verified that the device created had a strong performance in the evaluation process of learning by the students and, ultimately, that robotics is characterized as a powerful technology for the creation of devices for learning music support.

Keywords: Educational Robotics; Music Teaching; Orff Method.

\section{Introdução}

Desde a aprovação da Lei 11.769/2008, que versa sobre a obrigatoriedade do ensino da Música nas escolas de educação básica, muitos desafios devem ser enfrentados para que ocorra sua devida implantação. Dentre eles, a ausência de espaço físico específico, instrumentos - geralmente de alto custo - para a realização de atividades e o pequeno número de professores com formação específica em Música -, destaca-se que a Música será trabalhada na disciplina de artes.

Essa escassez de recursos em grande parte está relacionada à legislação, visto que o ensino de música ficou distante dos currículos escolares por aproximadamente quarenta anos, fazendo com que grande parte das instituições de ensino não a utilizasse como prática cotidiana e curricular. Esse contexto demanda pesquisas que adotem alternativas que potencializem e qualifiquem o ensino musical até que tenhamos melhorias na infraestrutura das escolas, ampliação da formação de educadores musicais 
e a viabilização da presença destes nas escolas.

Uma possibilidade consiste no desenvolvimento de recursos que possibilitem a construção do conhecimento musical a partir de ferramentas disponíveis dentro da própria escola, em especial aquelas do contexto social contemporâneo, marcado pela presença das tecnologias de informação e comunicação na escola, sobretudo a robótica.

Nesse sentido, o presente artigo apresenta os resultados de uma pesquisa que teve por objetivo explorar o potencial da robótica educativa como auxiliar no processo de ensino de Música. Para tanto, em um primeiro momento explorou os contornos de processos educativos no contexto da sociedade da aprendizagem (POZO, 2002). Em seguida, foca na exploração do conceito de Inteligência Musical presente na Teoria das Inteligências Múltiplas (GARDNER, 1994) enquanto componente de um contexto de aprendizagem. Por fim, à medida que exploramos a Lei 11.769/2008 e suas implicações práticas, apresentaremos o dispositivo robótico de baixo custo construído com base no xilofone Orff, instrumento musical comumente utilizado em processos de musicalização.

\section{A Aprendizagem de Música}

A concepção tradicional de aprendizagem baseada na apropriação e reprodução memorística dos conteúdos entrou em crise devido às mudanças sociais, tecnológicas e culturais próprias das sociedades modernas. Vivemos um momento que Pozo (2002, p.

32) denomina de sociedade da aprendizagem, na qual "a demanda de aprendizagens contínuas e massivas é um dos traços que define a cultura da aprendizagem de sociedades como a nossa."

A interação cotidiana, com as tecnologias e os constantes desafios que se colocam, exige a construção constante de novos conhecimentos e habilidades. Segundo Pozo (2002, p. 138), "aprender requer mobilizar nosso sistema cognitivo mediante múltiplos processos que vão além dos mecanismos de aquisição e mudança de nossos conhecimentos."

De acordo com os processos auxiliares da aprendizagem, Pozo (2002) preconiza que, para aprender, é preciso ter motivação, atenção para identificar os contornos do que se deseja aprender, recuperar o que aprendemos e, por fim, ter consciência de como dirigir a própria aprendizagem. Entre esses processos, esta pesquisa focou seus esforços analíticos na Recuperação e Transferência e na Consciência, detalhados a seguir.

A recuperação e transferência consistem na reconstrução dos nossos conhecimentos a partir de vestígios de outros conhecimentos anteriores. O que auxilia no reconhecimento é a presença de indícios conectados ou associados a uma representação, ou porque fizeram parte dela, ou porque estiveram presentes no contexto em que se aprendeu essa representação. Além da recuperação, é necessário transferir o que se aprendeu anteriormente para um novo contexto.

O segundo processo sobre o qual a pesquisa se debruçou diz respeito à consciência da própria aprendizagem. Implica aprender a utilizar nossos processos cognitivos de modo estratégico com a finalidade de alcançar determinadas metas de aprendizagem.

Esses dois processos, em um contexto de aprendizagem de música, demandam, ao menos nas etapas básicas de musicalização das crianças, um interlocutor que possa dar o feedback aos estudantes acerca das competências musicais envolvidas na reprodução de uma sequência rítmica ou harmônica, processo extremamente difícil para quem não tem formação musical. A partir dessa constatação, é importante resgatar o 
lugar da música em processos educativos.

\title{
2.1. A Música como elemento educativo e de desenvolvimento cognitivo
}

A valorização da música como fator educacional teve início na Grécia antiga, onde, juntamente com a filosofia e a matemática, era considerada essencial para $\mathrm{o}$ desenvolvimento da sociedade. Para os gregos, a música tinha poder de influenciar nas emoções e estados de espírito. No período Medieval, a música era parte integrante de um currículo chamado quadrivium, do qual também faziam parte a aritmética, a astronomia e a geometria (SANTOS, 1994). Os estudos de Gobbi (1999) apontam para a possibilidade de ampliação do desenvolvimento cognitivo a partir do trabalho com música, enfatizando que esse ensino não deveria ser apenas visto como uma fonte de prazer, mas de possibilidade de formação de sujeitos com capacidade de reflexão e abstração, diferentemente do que encontramos hoje nas escolas, cuja supremacia do ensino é calcada nas disciplinas de português e matemática. Ainda,

\begin{abstract}
A educação musical é um assunto que compreende muitas combinações, múltiplas atividades que envolvem a participação do aluno em nível sensóriomotor, quando o aluno trabalha ritmo, gestos e expressão corporal; em nível afetivo, quando retrata sensações e afetos; em nível social e em nível cognitivo, quando elabora uma composição, pensa uma música, interpreta. (GOBBI, 1999, p. 43).
\end{abstract}

Buscando aprofundar o conhecimento acerca do que podemos chamar de inteligência musical, Howard Gardner, em seu livro "Estruturas da Mente: A teoria das inteligências múltiplas", mostra uma pesquisa em neurobiologia, na qual percebemos áreas do cérebro humano que correspondem a determinadas formas de cognição. Segundo Gardner (1994, p. 78), "de todos os talentos com que os indivíduos podem ser dotados, nenhum surge mais cedo do que o talento musical." O desenvolvimento da competência musical não é estritamente um reflexo de habilidade inata, mas é suscetível a estímulos, apresentando forte relação com a cultura de uma sociedade.

Diante desse contexto acerca da importância da aprendizagem de música e suas implicações no desenvolvimento do indivíduo, diversos foram os músicos e educadores que desenvolveram propostas de ensino de Música, nas quais cada proposta refletia os interesses dos pesquisadores, bem como o contexto em que estavam inseridos. Entre as diversas abordagens que tiveram grande aceitação no Brasil, destaca-se a proposta de Carl Orff, apresentada a seguir.

\subsection{O método de aprendizagem Orff}

A essência da proposta pedagógica do músico-pedagogo alemão Carl Orff situa-se no que ele denomina educação musical elementar, conceito apresentado por Fonterrada (2003, p. 147) como uma "uma música primordial que envolvesse fala, dança e movimento, partisse do ritmo e servisse de base à educação musical da primeira infância”. A música elementar é realizada pessoalmente pelo indivíduo, que deixa de ser ouvinte e passa a ser participante, em um processo de interligação da experiência musical ao movimento corporal e à expressão plástica. Nesse sentido, todo conhecimento adquirido provém da experiência, o que o autor chama de fazer música.

No período em que trabalhava com as aulas de música e dança, Orff, juntamente com o construtor de instrumentos musicais Klaus Becker-Ehmck, desenvolveu o que ficou conhecido como Instrumental Orff, que é uma adaptação de instrumentos musicais 
direcionados para a educação elementar. Esse conjunto de instrumentos é classificado de acordo com sua construção e técnica de execução, sendo composto por flautas doces e instrumentos de percussão.

A família da percussão é dividida em instrumentos de afinação indefinida - da qual fazem parte bumbo, pandeiretas, triângulos, pratos, blocos sonoros, claves, castanholas, chocalhos, maracas - e afinação chamada também de instrumentos de plaquetas - xilofone baixo diatônico, xilofone contralto/soprano diatônico, metalofone contralto diatônico, jogo de sinos contralto/soprano cromático e jogo de sinos contralto diatônico (BONA, 2011, p. 145).

Tendo em vista a importância da utilização dos instrumentos de plaquetas dentro do contexto da abordagem Orff e considerando que cada instrumento pode ser utilizado ao mesmo tempo por uma ou, no máximo, duas crianças, seria necessária uma quantidade significativa para suprir a demanda de uma escola média. Levando em consideração que um xilofone ou metalofone fabricado no Brasil custa entre $\mathrm{R} \$ 400,00$ e $\mathrm{R} \$ 1.200,00$, o que varia de acordo com o modelo, torna-se inviável a compra em uma quantidade adequada, principalmente no que se refere à realidade das escolas públicas brasileiras. Nesse sentido, torna-se importante explorar alternativas para minimizar essas carências, sendo possível buscar ferramentas disponíveis dentro da própria escola, por exemplo, as tecnologias digitais.

\section{A robótica pedagógica livre como alternativa para a Educação Musical}

A Informática na Educação consiste em um dos temas de grande relevância que vem sendo discutido nas últimas décadas, especialmente em razão de diversas políticas públicas de inclusão digital que, de certa forma, popularizaram a presença de tecnologias nas Escolas ${ }^{1}$.

$\mathrm{Na}$ seara desse processo, uma das alternativas tecnológicas que tem se destacado e criado contextos desafiadores e motivadores aos estudantes é a robótica. No contexto educacional, diferente do aprendizado técnico em robótica - que prioriza instrumentos e códigos de programação em razão de uma demanda profisssionalizante geralmente relacionada à indústria, a robótica pedagógica tem como foco principal o desenvolvimento e design de protótipos com a finalidade de satisfazer uma demanda específica voltada ao ensino e aprendizagem de determinado assunto ou habilidade.

Ainda em relação ao termo robótica pedagógica, César $(2009$, p. 25$)$ a define como um "conjunto de processos e procedimentos envolvidos em propostas de ensino e de aprendizagem que tomam os dispositivos robóticos como tecnologia de mediação para a construção do conhecimento." Nesse contexto, desenvolveu-se a filosofia da robótica livre ${ }^{2}$, que parte de soluções livres em substituição aos produtos comerciais, a fim de criar soluções de baixo custo e abertas à modificação. Entre as características marcantes dessa alternativa tecnológica está o acesso ao código-fonte, condição necessária para que o seja considerada livre.

Nessa perspectiva, diversos projetos estão sendo realizados com a utilização do Arduino, uma plataforma de desenvolvimento open source com base em entrada e saída

\footnotetext{
${ }^{1}$ Reconhecemos que este processo possui muitas lacunas ligadas à manutenção dos laboratórios, à formação de professores e, principalmente na apropriação criativa e desafiadora destes dispositivos em um contexto de processos educativos. Entretanto, esta discussão, embora pertinente, afasta-se do escopo deste artigo.

${ }^{2}$ Disponível em: http://www.gnu.org/philosophy/philosophy.html.
} 
simples, que pode ser associada à criação de sistemas físicos que interagem através de hardware e software. Trata-se de um ambiente multiplataforma, ou seja, pode ser executado em qualquer sistema operacional. Tanto o software quanto o hardware possuem código aberto; portanto, o usuário tem a possibilidade de baixar o diagrama do circuito sem precisar pagar nada ao fabricante. Em relação à sua programação, o arduino possui um ambiente próprio que pode ser obtido diretamente do site do fabricante baseado na linguagem C/C++ (BANZI, 2011, p. 1-2).

\subsection{Protótipo Arduxylo}

No contexto desta pesquisa, desenvolveu-se um dispositivo robótico voltado ao ensino e aprendizagem elementar de música nas escolas, partindo do pressuposto de que é comum entre as escolas brasileiras de educação básica a escassez de instrumentos musicais e até mesmo de recursos financeiros para a aquisição destes. Partindo de pesquisas sobre o método de educação musical criado por Carl Orff, buscou-se, a partir da robótica livre, desenvolver um xilofone que tivesse como característica principal o baixo custo financeiro, possibilitando sua construção a partir de materiais alternativos encontrados na própria escola. Além disso, levando em consideração a não exigência por conta da Lei 11.769/2008 (BRASIL, 2015) - de professores com formação específica para ministrar aulas de música, implementou-se no dispositivo funções de automatização de processos que um professor sem formação específica não teria condições de conduzir.

O Arduxylo, como foi chamado, é um dispositivo robótico que representa um xilofone Orff. O dispositivo recebeu esse nome, uma vez que utiliza o Arduino como hardware principal. Desse modo, uniu-se um fragmento de cada uma das palavras "arduino" (ardu) + "xylophone" (xylo). A parte estrutural do Arduxylo, em sua versão final, foi desenvolvida a partir de peças do Kit Atto Educacional. Entretanto, o projeto pressupõe que sua construção possa ser realizada com qualquer material passível de montagem disponível nas escolas. Quanto aos demais materiais e componentes eletrônicos, foi utilizada uma placa Arduino MEGA 2560, além de leds, resistores, cabo UART, papel alumínio e canudos de plástico. A versão final do dispositivo custou, em média, R\$100,00. A seguir, destacamos o esquema de ligação do protótipo (Figura 1).

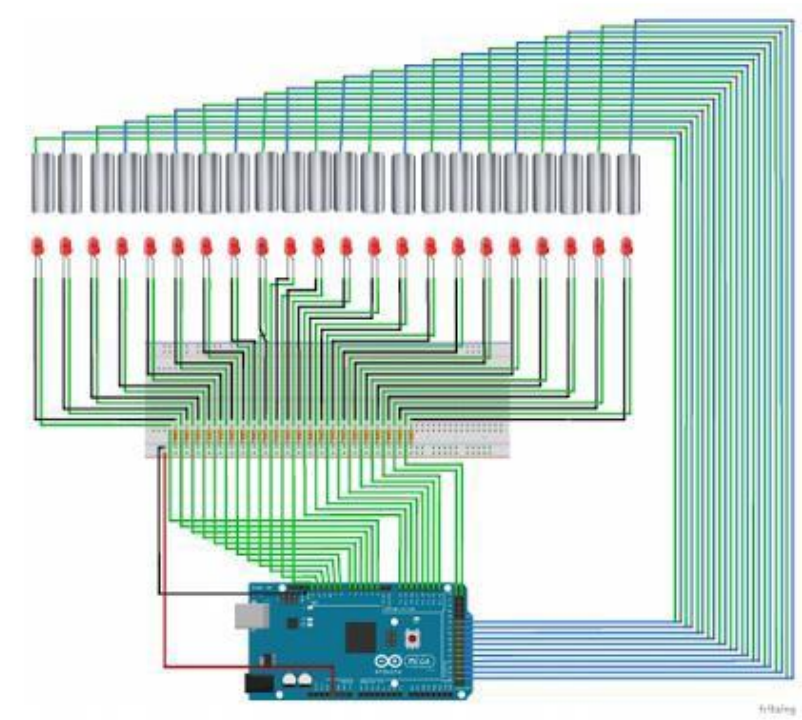


Figura 1 - Esquema de ligação do Arduxylo

Fonte primária (2017)

O Arduxylo (Figura 2) possui 22 teclas que estão dispostas em uma escala cromática que vai da nota Dó à nota Lá da oitava seguinte. Além das teclas que representam um xilofone Orff, dispõe de três pads com sensores que estão posicionados na lateral direita do Arduxylo, desenvolvidos com a finalidade de utilizar diferentes timbres de instrumentos de percussão. Tanto as teclas quanto os pads são revestidos com papel alumínio e funcionam através de um mecanismo de capacitância. $\mathrm{O}$ sinal é enviado ao Arduino no momento em que a capacitância do corpo humano é detectada por meio do toque na tecla pelas baquetas.

As baquetas (Figura 3), por sua vez, foram construídas a partir de canudos de plástico e revestidas com papel alumínio, contendo um fio condutor que passa por dentro do canudo e fica em contato com o papel alumínio nas duas extremidades. Ao tocar com a baqueta na tecla, o sinal passa a ser enviado ao software, transformando-o em som, que é emitido por meio dos alto-falantes do notebook conectado ao dispositivo.

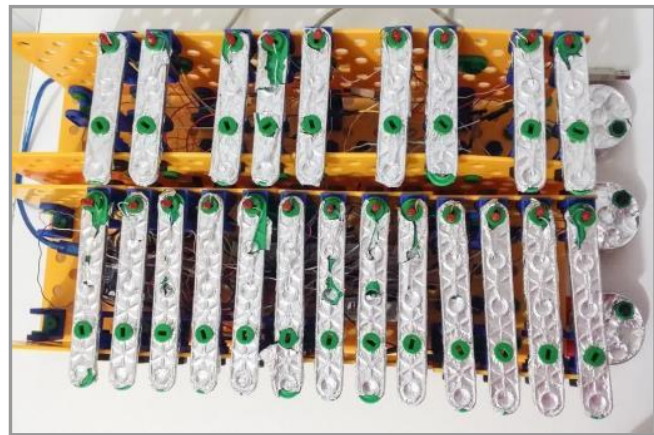

Figura 2 - Arduxylo

Fonte primária (2017)

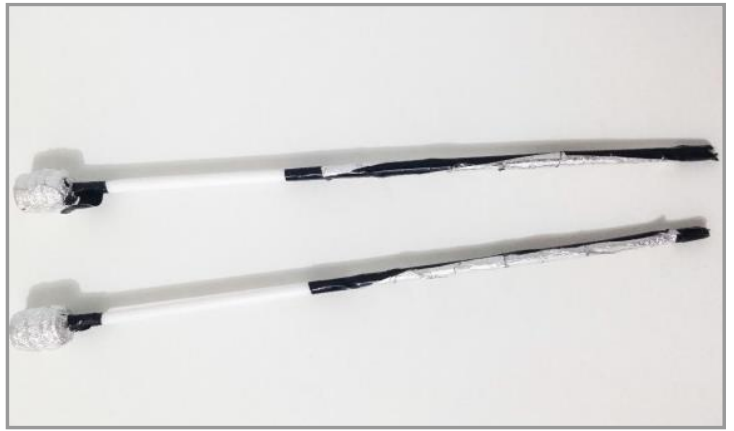

Figura 3 - Baquetas

Fonte primária (2017)

A questão do timbre do Arduxylo foi fator de grande importância no desenvolvimento desse protótipo, pois se utilizaram gravações do instrumento real, visto que pode servir de referência ao desenvolvimento da percepção auditiva dos educandos. Um dos elementos que torna o Arduxylo interessante é justamente a possibilidade de utilização de timbres de outros instrumentos musicais, por exemplo, a sonoridade de metalofone, instrumento também utilizado na proposta da metodologia Orff. Para utilizar os diferentes timbres, basta que o som respectivo de cada tecla seja gravado separadamente e importado para o software do protótipo em formato .wav.

Além de sua utilização na IDE do próprio Arduino, que é um ambiente de programação com diversas bibliotecas que auxiliam no desenvolvimento de projetos de códigos, desenvolveu-se um software (Figura 4) específico que possibilita a gravação de trechos musicais que podem ser salvos e, posteriormente, reproduzidos acendendo simultaneamente o led de cada tecla correspondente ao som emitido. Logo após, o educando pode tocar o trecho que acabou de ouvir. Se, porventura, for tocada alguma tecla que não está de acordo com a sequência da frase musical que escutou, todos os leds irão acender indicando o erro de execução e, automaticamente, o aluno será redirecionado ao início do exercício. Pensando em uma questão didática, o software possibilita a utilização de três diferentes andamentos, o que poderá ser útil de acordo com o nível de aprendizagem em que se encontra o aluno sobre determinado conhecimento musical. 


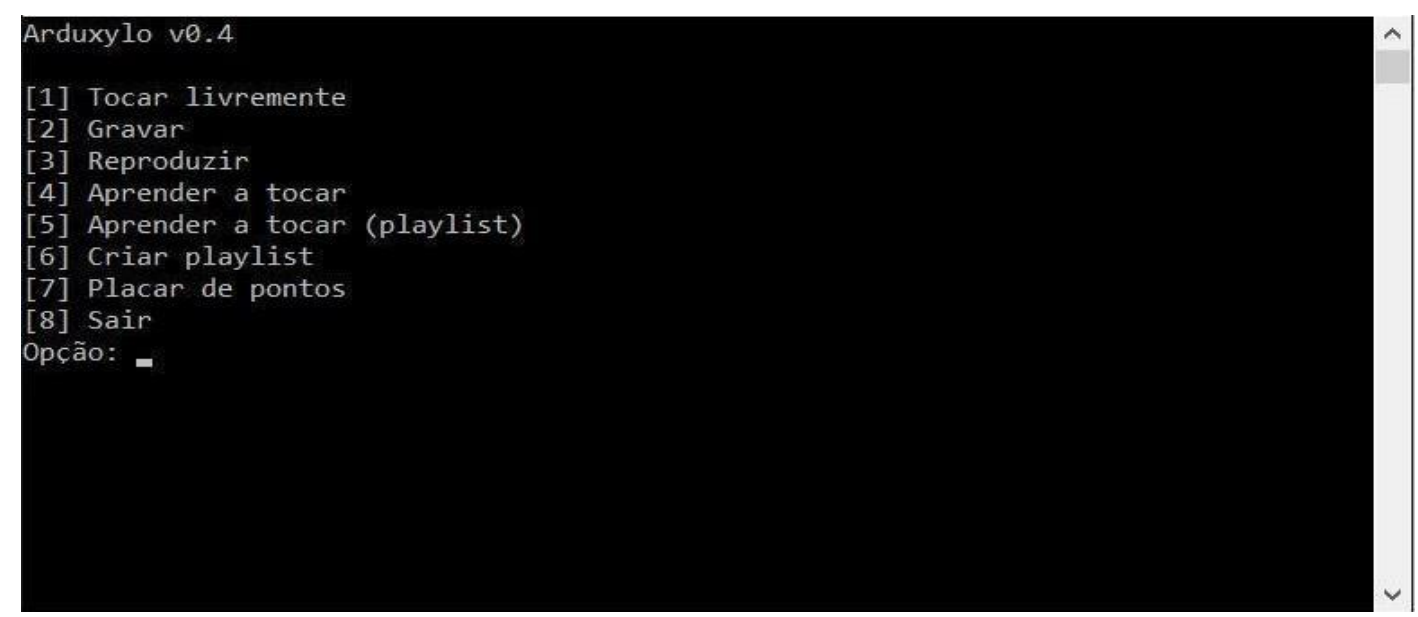

Figura 4 - Software do Arduxylo

Fonte primária (2017)

Conforme pode ser visto na imagem referente ao software do Arduxylo, a versão 0.4 conta com oito funções ${ }^{3}$. A opção 1 apresenta a possibilidade de tocar o instrumento livremente, sem que haja qualquer interação do dispositivo ou do software com o aluno. A possibilidade de gravar trechos musicais está presente na opção 2; esses trechos ficam salvos no software e, posteriormente, podem ser utilizados em outras funções. A opção 3 diz respeito à reprodução de trechos salvos, em que o led correspondente a cada tecla vai acendendo simultaneamente à emissão do som, para que, assim, o trecho musical possa ser ao mesmo tempo ouvido e visualizado. Já na opção 4 , o aluno poderá selecionar um dentre vários trechos musicais com a finalidade de aprender a tocar. Feita essa opção, o software reproduz o trecho quantas vezes o aluno achar necessário; posteriormente, quando selecionada a função de aprender a tocar, os leds acenderão indicando cada tecla que deve ser tocada.

$\mathrm{Na}$ opção 5, é possível selecionar uma playlist para aprender a tocar, que nada mais é que o mecanismo de fases do Arduxylo. A playlist é composta por vários trechos gravados sobre a mesma música, em que o professor poderá criar fases de acordo com o grau de dificuldade de cada trecho, visto que o software só libera a atividade da fase 2 após o aluno conseguir realizar corretamente a fase 1 e assim respectivamente. Tanto na opção 4 quanto na 5, o Arduxylo interage com o aluno por meio de frases de feedback que aparecem escritas na tela do notebook, por exemplo: "Você não executou corretamente esta frase musical, volte ao início" ou "Parabéns, você acertou!". A opção 6 possibilita a criação dessas playlists de forma simplificada. Basta selecionar uma ordem dos trechos já gravados anteriormente e, depois disso, nomear a playlist.

$\mathrm{Na}$ opção 7, é possível visualizar o placar de pontos de cada aluno, baseado no número de tentativas necessárias para realizar cada atividade. Esse placar também mostra o nome do aluno que conseguiu realizar a atividade com menor número de tentativas. Por fim, a opção 8 tem a função de sair do software (ANTUNES, 2016).

\section{Metodologia da pesquisa}

Visando verificar de que forma a utilização do Arduxylo pode auxiliar no processo de recuperação e transferência de conhecimento e no processo de consciência sobre a

\footnotetext{
${ }^{3}$ Link de acesso ao software do Arduxylo: https://goo.gl/oLsTHT.
} 
própria aprendizagem em atividades de musicalização, realizou-se uma pesquisa exploratória de cunho qualitativo com um grupo de quatro crianças na faixa etária entre 10 e 12 anos, estudantes de escolas públicas e residentes no município de Sertão, RS.

Com a finalidade de coletar dados para posterior análise, além da observação, foram utilizadas gravações de vídeo; após o período das oficinas, foi realizada uma entrevista individual com perguntas abertas, a fim de obter outros elementos a serem contrapostos aos dados das observações. Embora a abordagem Orff de educação musical tenha como proposta o ensino de música para todas as idades, foi necessário escolher uma faixa etária específica para a elaboração e desenvolvimento das atividades a partir da utilização do Arduxylo.

Em virtude do objetivo da pesquisa, o software do Arduxylo foi desenvolvido com o intuito de auxiliar o aluno no desenvolvimento do processo de recuperação e transferência da aprendizagem e no processo de consciência sobre como dirigir a própria aprendizagem. Em relação ao primeiro, o mecanismo de fases funciona como uma espécie de jogo, contribuindo para que o educando recupere o que foi aprendido e possa transferir para o novo exercício. Quanto ao processo de consciência, o Arduxylo conta com um mecanismo de leds que acendem sempre que o aluno executa de forma equivocada uma frase. Esse mecanismo de leds funciona como uma espécie de feedback imediato, auxiliando no desenvolvimento da consciência sobre sua própria aprendizagem.

Embora os exercícios propostos para serem desenvolvidos com o Arduxylo sigam uma sequência de etapas nas quais a criança precisa vencer o primeiro exercício para ser direcionada ao próximo, o software possibilita que o professor trabalhe com exercícios de diferentes etapas de modo aleatório. Isso se justifica pelo fato de que a criança pode apresentar dificuldade em desenvolver determinada habilidade nos primeiros exercícios, mas talvez consiga desenvolvê-la em outro momento.

Partindo do estudo acerca desses dois processos auxiliares da aprendizagem, foi possível delinear seis categorias de análise que ajudaram a verificar de que forma a utilização do Arduxylo auxilia no desenvolvimento do processo de recuperação e transferência e de consciência, sendo elas: reconhecimento, evocação, transferência, planejamento de uma tarefa, regulagem e execução, avaliação.

\subsection{Oficinas}

$\mathrm{Na}$ sequência, serão descritas as atividades realizadas durante as quatro oficinas. Essas atividades foram elaboradas a partir da abordagem Orff de educação musical, tendo como objetivo desenvolver habilidades musicais a partir da utilização do dispositivo robótico construído nesta pesquisa.

$\mathbf{1}^{\text {a }}$ oficina: teve como objetivo desenvolver habilidades de pulso rítmico e melodia, partindo de atividades que contemplem o movimento e os sons corporais. Em um segundo momento, essas mesmas habilidades, desenvolvidas fora do instrumento, foram trabalhadas com a utilização do Arduxylo. No início da oficina, foi escolhida a canção "Marcha Soldado" por ter melodia simples e apenas dois acordes. Ao mesmo tempo que a música era cantada, os alunos caminhavam nos tempos alternando os pés direito e esquerdo; dessa forma, trabalhando o pulso rítmico. Em segundo momento, foi trabalhada a letra cantada, de modo a instigar os alunos à análise da música, sua letra, significado das palavras, contexto em que foi criada, bem como algumas curiosidades. Posterior a essa atividade, os alunos foram organizados em círculo, a fim de que pudessem visualizar uns aos outros, marcharam no sentido horário respeitando os 
tempos da música, buscando desenvolver a pulsação rítmica através dos movimentos corporais. Por fim, essas habilidades desenvolvidas no decorrer da oficina foram também trabalhadas no Arduxylo, em que os alunos realizaram atividades rítmicas utilizando os sensores de percussão.

$2^{\mathbf{a}}$ oficina: nessa oficina, continuaram-se as atividades envolvendo pulso rítmico, acrescentando a harmonia através da execução de duas teclas simultâneas por acorde. Outro elemento desenvolvido nessa oficina foi o contratempo. Em primeiro momento, repetiu-se o último exercício da oficina anterior relacionado ao pulso rítmico. $\mathrm{Na}$ sequência, a voz foi utilizada como recurso melódico através do canto e, simultaneamente, a marcação do pulso rítmico foi realizada por cada aluno individualmente tocando os sensores rítmicos do Arduxylo. A percepção das mudanças harmônicas foi trabalhada por meio do exercício de andar em círculo respeitando os tempos da música; conforme a ocorrência de mudança harmônica, era necessário inverter o sentido da roda de horário para anti-horário e vice-versa. Após terem desenvolvido essa habilidade, um exercício de harmonia foi trabalhado utilizando o Arduxylo.

No momento em que a melodia da música estava sobre o acorde de Dó, os leds referentes às teclas Dó e Sol acendiam no tempo da música, indicando o momento certo em que as notas deveriam ser tocadas; já nos trechos em que a música estava em Sol, os leds das teclas Ré e Sol eram acesos. A última atividade dessa oficina visou ao desenvolvimento do contratempo. Enquanto todos os participantes cantavam a música, o desafio foi caminhar nos tempos e bater palmas nos contratempos.

$3^{a}$ oficina: nessa etapa do processo, os alunos já deveriam ter desenvolvido o pulso rítmico, o contratempo, a percepção das mudanças harmônicas, bem como o canto da melodia. Nessa oficina, foram trabalhados outros instrumentos utilizados no arranjo dessa música, em forma de repetições e ostinatos ${ }^{4}$. No início da atividade, a ideia foi trabalhar com a habilidade de contratempo desenvolvida na oficina anterior por meio de sons corporais, porém utilizando o Arduxylo. Para isso, enquanto a música era cantada, o exercício individual foi de marcação do contratempo nos sensores rítmicos do Arduxylo. Outra atividade estava relacionada à execução da linha do baixo do protótipo, região grave do Arduxylo. A linha do baixo, que nesse caso corresponde à harmonia da música, foi construída com poucas notas sucessivas e não simultâneas, como na oficina anterior, e desenvolvida em forma de ostinatos. Cada led aceso indicava a tecla e o momento de sua execução, não necessitando da ajuda do professor nesse momento.

$4^{\text {a }}$ oficina: nessa fase da pesquisa, buscou-se trabalhar a melodia da música, visto que diversas habilidades já haviam sido desenvolvidas nas oficinas anteriores. A execução da melodia pode ser considerada como a mais complexa de todas as habilidades trabalhadas no decorrer das oficinas, visto que, diferentemente das demais, esta não se encaixa na lógica de repetição. Essa atividade foi realizada por cada aluno individualmente; era necessário tocar a tecla correspondente ao led aceso. Conforme algumas ocorrências em que se tocou alguma tecla errada ou não, respeitou-se o tempo da nota, todos os leds eram acesos indicando erro de execução, e assim o exercício era reiniciado.

\subsection{Apresentação e análise dos resultados}

4 Frase musical que é persistentemente repetida numa mesma altura podendo ser um padrão rítmico, parte de uma melodia ou uma melodia completa. 
Diante dos dados coletados, foi possível perceber que a categoria de análise que mais se destacou durante as quatro oficinas foi a avaliação, seguida da regulagem e execução e, posteriormente, do planejamento de uma tarefa. As demais categorias que se referem ao processo de recuperação e transferência - reconhecimento, evocação e transferência ocorreram em uma menor frequência.

Acreditamos que isso se deve ao fato de que os alunos possuíam diferentes níveis de conhecimento musical e dispúnhamos somente de uma unidade do Arduxilo. Soma-se a possibilidade de que a realização de mais oficinas possibilitaria a criação de situações nas quais tais processos poderiam ser vivenciados e observados mais vivamente.

Podemos supor, com base nos dados coletados, que os mecanismos de feedback do Arduxylo auxiliaram os alunos principalmente no desenvolvimento da avaliação de sua aprendizagem. Isso ocorreu por meio de um conjunto de elementos, por exemplo: os leds que acendiam simultaneamente indicando erros; a interface do software, que, através de mensagens escritas, indicava acertos e erros; pelo sistema de fases, em que é necessário vencer um exercício para poder realizar a atividade seguinte. Acreditamos que essas funções contribuíram substancialmente para que as manifestações dos quatro alunos se enquadrassem, na maioria das vezes, na categoria avaliação. Tendo em vista a experiência dos pesquisadores na área de educação musical e tomando por base a técnica tradicional de realização dos mesmos exercícios em um xilofone Orff, acreditamos que os alunos não teriam as mesmas percepções quanto à autoavaliação sem a utilização do dispositivo e na presença de um professor sem formação em Música.

\section{Considerações finais}

A partir da análise dos dados coletados, observamos que o Arduxylo foi capaz de auxiliar no desenvolvimento do processo de recuperação e transferência e, sobretudo, no processo de consciência sobre como dirigir a própria aprendizagem. Por meio da utilização das categorias de análise, percebemos um grande número de incidências no processo de consciência, principalmente em relação à categoria avaliação. Acreditamos que isso está relacionado muito ao sistema de leds e ao software, que funcionaram como um constante feedback.

Com o estudo, foi possível construir um dispositivo robótico de baixo custo capaz de implementar ações ou processos que um professor sem formação específica em Música muito provavelmente não conseguiria. Além disso, ao se consolidar como software e hardware livres, o Arduxilo demonstra potencial para ampliação dos recursos oferecidos para a aprendizagem de Música.

\section{Referências}

ANTUNES, S. F. Robótica livre como alternativa didática para a aprendizagem de música. 2016. 93 f. Dissertação (Mestrado em Educação) - Universidade de Passo Fundo, Passo Fundo, RS, 2016.

BANZI, M. Getting started with arduino: the open source eletronics prototyping plataforma. 2nd edition. Tokyo, 2011.

BONA, M. Carl Orff: um compositor em cena. In: MATEIRO, Teresa; ILARI, Beatriz. (Org.). Pedagogias em educação musical. Curitiba: IBPEX, 2011.

BRASIL. Lei n. 11.769, de 18 de agosto de 2008. Altera a Lei no 9.394, de 20 de 
dezembro de 1996, Lei de Diretrizes e Bases da Educação, para dispor sobre a obrigatoriedade do ensino da música na educação básica. Brasília, DF, 2008. Disponível em: < https://goo.gl/LX6VaU>. Acesso em: 10 mar. 2015. CÉSAR, D. R. Potencialidades e limites da robótica pedagógica livre no processo de (re)construção de conceitos científico-tecnológicos a partir do desenvolvimento de artefatos robóticos. 2009. Dissertação (Mestrado em Educação) - Faculdade de Educação, Universidade Federal da Bahia, Salvador, 2009.

FONTERRADA, M. T. O. De tramas e fios: um ensaio sobre música e educação. São Paulo: Ed. da Unesp, 2003.

GARDNER, H; BARBOSA, M. C. S. Estruturas da mente: a teoria das inteligências múltiplas. Porto Alegre: Artes Médicas, 1994.

GOBBI, V. A educação estética através da apreciação musical: uma experiência. 1999. Dissertação (Mestrado em Educação) - Universidade de Passo Fundo, Passo Fundo, 1999.

POZZO, J. I.; MORTIMER, E. F. Aprendizes e mestres: a nova cultura da aprendizagem. Porto Alegre: Artmed, 2002.

RICHARDSON, R. J. Pesquisa social: métodos e técnicas. 3. ed. São Paulo: Atlas, 2008.

SANTOS, R. M. S. A natureza da aprendizagem musical e suas implicações curriculares: análise comparativa de quatro métodos. In: ABEM. Fundamentos da educação musical, série 2, p. 7-112, jun. 1994. 